\title{
Cost-effectiveness in health: consolidated research and contemporary challenges
}

Eric Kaun dos Santos Silva ${ }^{1}$, June Alisson Westarb Cruz (ib) ${ }^{1,2}{ }^{凶}$, Maria Alexandra Viegas Cortez da Cunha ${ }^{2}$, Thyago Proença de Moraes', Sandro Marques ${ }^{1,3}$ \& Eduardo Damião da Silva ${ }^{1}$

The need to develop alternatives to improve health assistance access and qualification was emergent and urgent even before the advent of Covid-19. Such demand is necessary in regard to both public and private systems. In this context, the theme of cost and effectiveness is technically adequate and viable to analyze these alternatives. Analyzing the history of research development on the topic and identifying its gaps is thus an essential step in facing this challenge. Therefore, the objective of this study was to modestly contribute to a bibliometric examination of scientific production based on the theme of cost-effectiveness to guide future research, despite the maturity of the theme, and as well as its future challenges. As a result, several essential aspects of the theoretical approach to the theme were observed, such as its conceptualization, purpose, and objective within public and private institutions, identifying its main authors, universities, reference countries, and funding institutions, authors' relationship networks, and related themes. One of the most important factors identified is the absence of the theme applied to contemporary topics in health, such as telemedicine, telehealth, robotics, artificial intelligence, new drugs and medicines, and new healthcare protocols.

\footnotetext{
${ }^{1}$ Pontifical Catholic University of Paraná, Curitiba, Brazil. ${ }^{2}$ Fundação Getúlio Vargas-EAESP, São Paulo, Brazil. ${ }^{3}$ Stanford University—EUA, Stanford, CA, USA.

凶email: june.cruz@pucpr.br
} 


\section{Introduction}

he advancement of technology and applied science in health has developed rapidly in recent years; thus, there is a need for investment in new treatments, equipment, and trained staff. However, the monetary resources of health institutions, as well as of society, are scarce, demanding a search for constant resource maximization and efficient allocation. For this reason, health administrators and managers seek indicators that effectively corroborate the understanding of which strategies, technologies, protocols, and devices, among others, are most interesting to treat and/or offer to patients. Therefore, the understanding of themes related to the analysis of the cost and effectiveness of healthcare contributes to the design of more assertive strategies in the allocation of resources, improving the institution's competitive performance, that use assessments to better allocate their resources.

There are different types of evaluation in this area: costconsequence analysis, cost-minimization analysis, costeffectiveness analysis (CEA), cost-utility analysis, cost to the user (Vuong, 2015) and cost-benefit analysis. These analyses provide managers with a coherent and explicit approach with a theoretical basis to assess costs and results, in addition to helping them manage uncertainties (Zequinão et al., 2020). Therefore, economic evaluation is indispensable in this context as it allows the inclusion of all essential information to choose the best option. This also creates a space to compare new technologies linked to the strategic purpose of improving healthcare access in several communities, whether from the Health Sector.

Against this background, this article presents as a general objective, to identify the main characteristics of scientific research inherent to the theme of cost-effectiveness in health sector, by answering the following questions: What are the main authors of the topic cost-effectiveness in health? What are the main universities that promote research in the area of cost-effectiveness in health? What is the quantitative historical series of research related to the theme? Which main countries promoting research linked to the theme? What are your main research and networks of influence? And finally, which main themes are added to the theme, in the health sector?

In particular, the novelty of this research is confirmed by the absence of bibliometric research focused on the theme of cost-effectiveness and thematic related to health, in a broad way. This statement is based on the analysis of web of science research, which presents 21 studies that apply bibliometric as a method of cost-effectiveness analysis in the health sector, all with specific applications to the analysis of clinical and surgical pathologies, therefore, none of them presents a broad and integrated analysis of the theme, as presented in the present research.

This article is presented as a fundamental part in the construction of applied research to analyze cost-effectiveness in health sector, corroborated, at this stage, by the theoretical understanding of the theme CEA. Thus, a bibliometric analysis on the topic is presented below. Mirrored in the experience of (Secoli et al., 2010), this search was conducted via the Web of Science database. In the survey, the descriptors were used in combination with suitable Boolean operators to obtain accurate data according to the needs. The time interval considered was from 1977 to 2020, resulting in a sample of 7972 studies delimited in the articles category (Table 1).

This study's results aim to provide future applied research with relevant and reliable theoretical bases, in addition to benefitting future studies by offering essential element mapping to support the future research directions.

\section{Methods}

The search in databases, including the Web of Science (WoS) platform, used keywords as the search strategy (Sandri et al., 2020). All fields were included, including the themes "costconsequence analysis in health, cost-minimization analysis in health, cost-effectiveness analysis in health, cost-utility analysis in health and cost-benefit analysis in health" using the "OR" bead. Operationally, the research took place in five stages: (1) definition of the research strategy; (2) data collection in the databases selected for the study and data export; (3) organization and integration of the databases and graphic layout; (4) analysis of the results with identification of patterns and factors of relevance; (5) finally, analysis of scenarios, trends, and practical implications.

The analysis included quantitative data by period since the beginning of the base. The country of origin of the study was evaluated for information on the dissemination of study results. Moreover, an analysis of publications by university and authors was included. The Vosviewer software (www.vosviewer.com, University Leiden) was used to analyze the relevance of universities.

Finally, reinforcing the justification of the novelty and contribution of the approach of the present research, the following are the research inherent to the theme, which address more specifically bibliometric methods of analysis applied to the theme of Cost-Effectiveness and related themes:

Through the content analysis of the research listed, it was possible to perceive the application of bibliometric in a very specific way in certain pathologies, except for Pitt et al. (2016) research. Moreover, not presenting the analysis of the theme costeffectiveness in health sector in an integral and updated way.

Cost-effectiveness: a conceptual approach. The search for strategic alternatives to access and qualify health services has been a constant aspiration worldwide (Meunning, 2008). Technology solutions, for example, have changed quickly, and there is pressure to introduce new techniques that at first sight may seem tempting, even without more detailed feasibility studies. Demand for increasingly effective treatments by the public, as well as population aging, have necessitated strategic changes in health sector (Jacobs et al., 2006). As a result, the challenge for managers in the area is to balance the growing demand concomitantly with the limited budget of health entities and the limited ability of users to pay (Loesch et al., 2021).

In this sense, two elementary economic and administration theoretical premises help to understand this reality: the scarcity of resources and the unlimited needs of agents (Moreno et al., 2019). In general, societal demands increased product or service consumption; however, the means to serve all people are limited. Health is no different, as there are insufficient resources to provide the most expensive and efficient treatments to the entire population (Loesch et al., 2020). A constant tradeoff was identified, and managers have many questions regarding resource allocation. It is necessary to find viable alternatives to balance limited resources and health service provision (Zequinão et al., 2020), promoting in this way, greater access to health care users, especially the poorest (Vuong, 2015).

This ratio creates the need to structure better resource allocation, that is, to consciously use monetary capital in treatments that maximize healthcare access and quality; that is, it is essential to seek operational and strategic effectiveness to achieve superior performance (Gasparetto et al., 2019).

Many factors can affect the strategic choices of health institutions, both internal, such as choosing treatments to be offered, buying new equipment, offering specialized services, and hiring professionals, and 
Table 1 Bibliometric studies on the effectiveness of Cost in the health sector during the period 2005-2021.

Authors

Loonen, MPJ; Hage, JJ; Kon, M

Castiel, LD; Sanz-Valero, J

Espallargues, $\mathrm{M}$ et al.

Waugh, $\mathrm{N}$ et al

Guthrie, $S$ et al.

Royle, P; Waugh, N

Del Bo, CF

Hernandez-Villafuerte, K; Li, R;

Hofman, KJ

Pitt, C; Goodman, C; Hanson, K

Coast, J

Fonseca, BDFE et al.

Roh, S; Tae, S; Kim, R

Grega, D; Kolar, J

Martinho, VJPD

Srihari, KNS; Choudhary, NR;

Subramanya, $\mathrm{P}$

Tran, BX et al.

Gheorghe, A; Gad, M; Ismail, SA

Chalkidou, $\mathrm{K}$

Rezapouri, A et al.

Yeo, JS; Jeong, Y

Burton, MJ et al.

Nazaripour, $\mathrm{M}$ et al.

\section{Article Title}

Year

Who benefits from peer review? An analysis of the outcome of 100 requests for review by Plastic and

Reconstructive Surgery

Between fetishism and survival: are scientific articles a form of academic merchandise?

The opinion of practitioners and internists on the impact of health technologies introduced in the last 25 years

Screening for cystic fibrosis-related diabetes: a systematic review

The impact of the National Institute for Health Research Health Technology Assessment program, 2003-13: a multimethod evaluation

Bibliometrics of NIHR HTA monographs and their related journal articles

The rate of return to investment in R\&D: The case of research infrastructures

Bibliometric trends of health economic evaluation in Sub-Saharan Africa

Economic Evaluation in Global Perspective: A Bibliometric Analysis of the Recent Literature

A history that goes hand in hand: Reflections on the development of health economics and the role played by Social Science \& Medicine, 1967-2017

South-south collaboration on HIV/AIDS prevention and treatment research: when birds of a feather 2018 rarely flock together

Developing a Green Building Index (GBI) Certification System to Effectively Reduce Carbon Emissions in South Korea's Building Industry

Historical analysis of pharmacoeconomic terms

Best management practices from agricultural economics: Mitigating air, soil and water pollution

Evidence base of yoga studies on cardiovascular health: A bibliometric analysis

Economic evaluation studies in the field of HIV/AIDS: bibliometric analysis on research development and scopes (GAP(RESEARCH))

Capacity for health economics research and practice in Jordan, Lebanon, the occupied Palestinian territories and Turkey: needs assessment and options for development

Health Economic Evaluation in Iran (1998-2017), a Bibliometrics Analysis

Pathway toward market entry of perovskite solar cells: A detailed study on the research trends and collaboration networks through bibliometrics

The Lancet Global Health Commission on Global Eye Health: vision beyond 2020

2019

Research trends of heavy metal removal from aqueous environments

external, such as economic and demographic trends in country, regulations, consumer behavior, competitors, suppliers, market characteristics (Devers et al., 2003), and the sensitivity of health consumers to the costs inherent in treatment (Vuong et al., 2018).

When establishing a strategic position, the focus should be on directing resources toward procedures that create value for the client, generating economic gains for the health organization or, in the case of public systems, making the operation feasible. To achieve this goal, according to (Secoli et al., 2010), health sector is increasingly trying to improve efficiency. For this reason, health administrators and managers seek indicators that effectively corroborate the understanding of which equipment, techniques, and mechanisms are more interesting to treat and/or offer to patients (Briggs et al., 2006; Tuon et al., 2019). This means that the use of these indicators contributes to the design of more assertive strategies in resource allocation, resulting in more competitive and sustainable institutional performance (Gasparetto et al., 2019).

The device commonly used to better allocate resources is the assistance and economic evaluation of health programs. In this context, there are different types of evaluations in this area. These indicators provide a coherent and explicit approach with a theoretical basis to assess costs and results in addition to helping managers address uncertainties (Gray et al., 2010). Therefore, economic evaluation is indispensable in this area, since it allows for the inclusion of all essential information in choose the best option while creating a space to compare new technologies. In addition, it creates a space to compare new technologies with treatments from other categories (Loesch et al., 2020) and allows a better support of users of health services in relation to mitigating relevant form their sensitivity to the expenses inherent to treatment (Vuong et al., 2018).
In this compendium, efforts will be directed toward the theoretical understanding of CEA. In this context, costeffectiveness is utilized to measure the impact of two or more treatment alternatives and to identify the options with the best health assistance outcomes, resulting in less need for resource allocation (Zequinão et al., 2020). In this analysis, costs are measured in monetary value and the effects of treatment in natural effectiveness units, such as years of life gained or improved functional status (Secoli et al., 2010), or even, improving access to health care (Loesch et al., 2021).

Therefore, the first step to conduct a CEA is to establish the costs and effects of one or more interventions. Subsequently, the cost difference between alternatives and between effects is calculated (Tuon et al., 2020), and finally, these differences are presented as a ratio, that is, cost per unit of result or health effect (Gray et al., 2010).

In CEA, the options to be compared can be placed in a costeffectiveness plane. The graphic reproduction of the point where the $\mathrm{x}$ and $\mathrm{y}$ axes intersect indicated in the plane shows the point of origin of costs and effectiveness for the standard factor of comparison (Tuon et al., 2020). Figure 1 shows this graphic result.

Thus far, the function of the analyses estimated by CEA is to identify cost-effective alternatives. In other words, a treatment can be considered cost-effective through a comparative process (Secoli et al., 2010). To facilitate understanding, this case is exemplified in Table 2.

Table 2 shows that treatment A is more cost-effective than the others as it allocates fewer resources to obtain one day without symptoms. Treatment B is the least indicated, as it has the worst cost-effectiveness. 


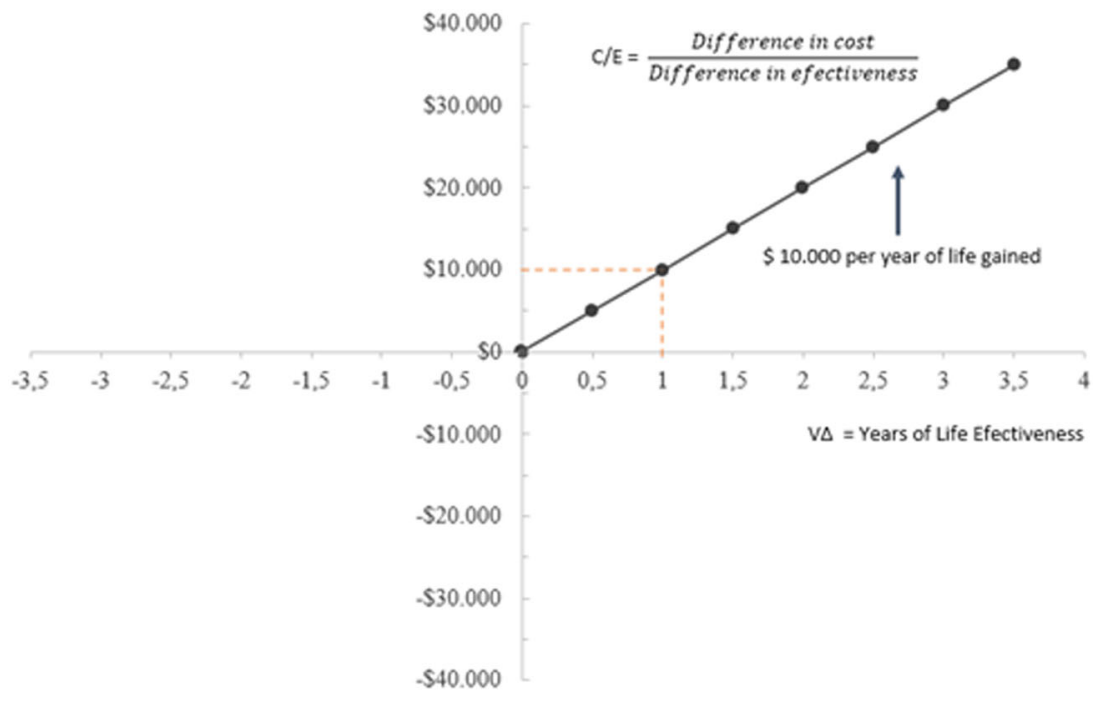

Fig. 1 Cost-effectiveness plane. Source: [12].

\begin{tabular}{|c|c|c|}
\hline & Cost (\$) & Effectiveness (without symptoms) \\
\hline Treatment $\mathrm{A}$ & 2.500 & 4 \\
\hline Treatment B & 3.300 & 3 \\
\hline Treatment C & 4.200 & 6 \\
\hline Treatment D & 3.000 & 4 \\
\hline
\end{tabular}

Cost-effectiveness Ratio

625/Day without symptoms 1100/Day without symptoms 700/Day without symptoms 750/Day without symptoms

Source: adapted from [12].

The result of the CEA is referred to as the incremental costeffectiveness ratio (ICER), which can be demonstrated as follows: if there are two options, $a$, and $b$, first their respective costs and effects should be measured, then the difference between costs and between effects is calculated, and finally ICER is calculated, as shown below (Gray et al., 2010):

$$
\operatorname{ICER}=\frac{\operatorname{Cost}(\mathrm{a})-\operatorname{Cost}(\mathrm{b})}{\operatorname{Effect}(\mathrm{a})-\operatorname{Effect}(\mathrm{b})}=\frac{\Delta \text { Cost }}{\Delta \text { Effect }}
$$

As previously mentioned, the effects of each intervention can be calculated using different measurement units; for example, the analysis of two blood pressure treatments could be compared by the cost of a $1 \mathrm{mmHg}$ reduction in systolic blood pressure (Gray et al., 2010). Although some authors state that there is no consensus as to which measure of effect should be used and suggest that there is no single appropriate measure for every situation, other authors propose using multiple measures based on willingness to pay for each unit of effect (Secoli et al., 2010).

Consequently, the ideal would be an equivalent measure to be used for different procedures. In this case, the measure that is considered most convenient and practical and that is disseminated by the specialists is the quality-adjusted life-year (QALY) (Gray et al., 2010).

QALY can be understood as an attempt to measure how many years of life with reasonable quality a person can gain due to the treatment. (Secoli et al., 2010) elucidates this concept very simply: imagine the quality-of-life changes that occur when a person with diabetes receives a medication to reduce blood sugar. Over time, this treatment can prevent a myocardial infarction, which would have a serious impact on health sectorand, in turn, would affect the person's quantity and quality of life. Consequently, QALY is a measurement that provides a more understandable comparison among therapies of different categories.
Sensitivity analysis, on the other hand, is a technique for assessing uncertainty "about any and all covariables contemplated in the economic model, that is, regarding costs or outcomes" (Secoli et al., 2010). That is, the technique attests to the degree of stability or robustness of the results (Loesch et al., 2021).

Therefore, this study demonstrates a brief conceptualization of what CEA, considered a fundamental concept in health sector that has substantially progressed in the last three decades, is: a pragmatic indicator that simplifies the alternatives for administrators in the face of budget limitations (Drummond et al., 2015). It also provides a systematic understanding of therapies based on their respective cost-effectiveness in addition to comparing different classes of treatments using the QALY. Thus, it is considered a method for economic health assessment that significantly contributes to strategy design by organizations operating in the sector as well as being essential to maintain high performance with the rapid changes that occur in the competitive market.

Finally, the concepts presented in this chapter of the research, are addressed in the most varied forms in scientific production in the world, and therefore, evaluating and demonstrating its characteristics, status, researchers, universities, among others is vital, for the identification of research opportunities and needs, without the unnecessary overlap of theories, methods, and research objects.

Cost-effectiveness: bibliometric analysis. The theme of CostEffectiveness has developed noticeably in the last ten years (Fig. 2). From 2009 to 2020, the number of publications more than doubled, starting at 294 at the beginning of this period and reaching 717 last year, shining light on concerns in the health sector to deepen discussions on the evaluation of costs and results in the analysis of therapy options. 


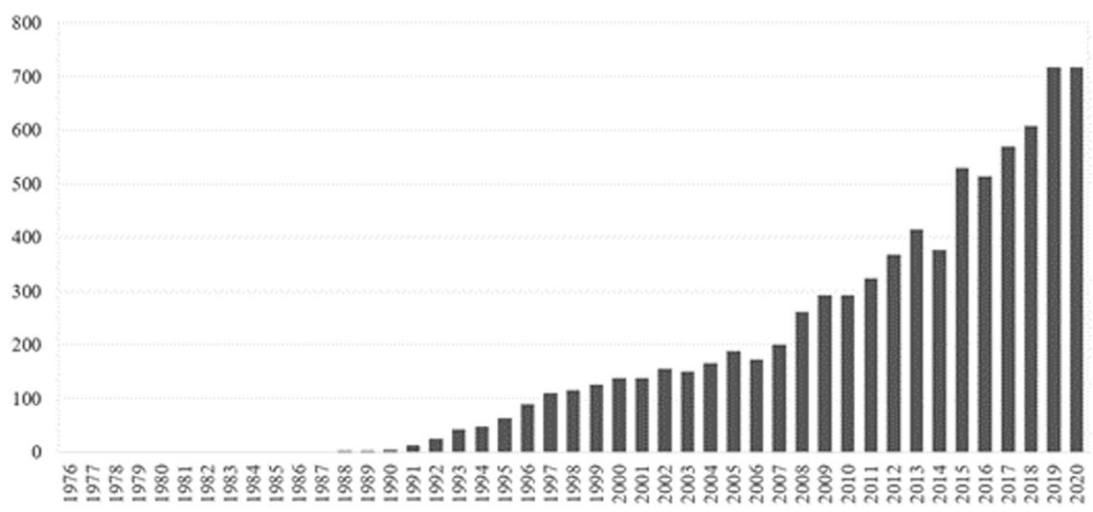

Fig. 2 Publications by year. Source: Web of Science, 2021.

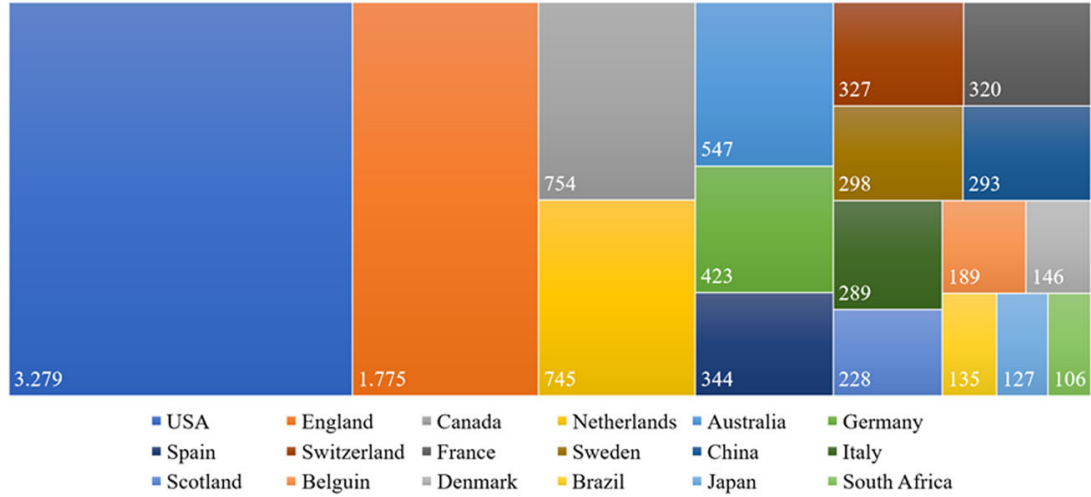

Fig. 3 Publications by country. Source: Web of Science, 2021.

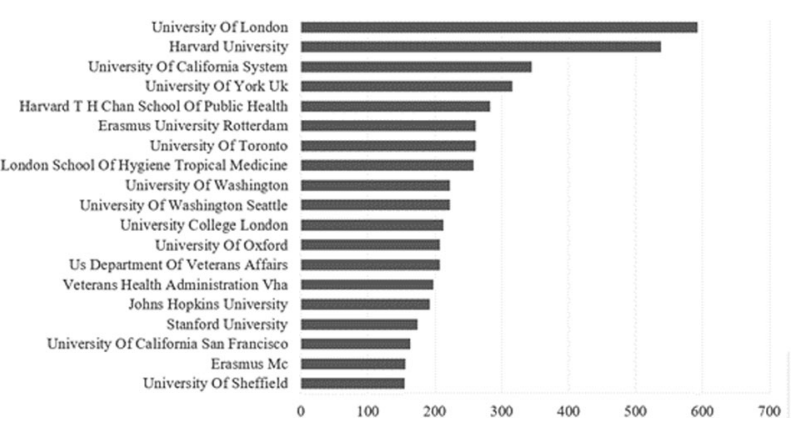

Fig. 4 Publications by institution. Source: Web of Science, 2021.

This subject emerged in the 1970s but with little relevance. It is possible that, in the past, other methods were preferable due to the poor availability of information in addition to the belief that economic evaluation in health sector was poorly structured, as it was a method originating from economics, requiring a significant effort from academics for its transition and conceptual adaptation. In addition, budgetary limitations of public and private institutions stimulated research on this topic, possibly aiming at alternatives to decrease the complexity of these sectors, especially health sector.

As for the hierarchy of publications separated by country of origin, Fig. 3 shows a prevalence of publications in the United States, with 3279 studies, followed by 1775 from England and 754 from Canada. Brazil appears in the list with 135 studies, ahead of developed countries like Japan, with 127 articles and South Korea, with 55. These results may be related to the dimension of the health sector of these countries because, for example, the United States invests about $15 \%$ of their GDP in health sector, while
England has a universal health sector like Canada. Although it presents an incipient amount, the Brazilian case also deserves special attention, since health represents $9 \%$ of its GDP (IBGE, 2021), with a broad public health sector, which currently serves $\sim 74 \%$ of the population (National Health Agency, 2021). Therefore, it is assumed that scientific development may be linked to the size of demand in each territory (Fig. 4).

Analysis of the centrality of the institutional link of the studies shows the relevance of the University of London, presenting a total of 593 published studies, followed by Harvard, with 538, and the University of California System, with 345. This list also includes some Brazilian universities, with USP presenting the most publications, at a total of 34 , followed by UFRJ and UNIFESP, both with ten studies.

The authors of greater quantitative relevance, not considering their potential citations, are Neumann, with 68 publications, Weinstein, with 59, and Sculpher, with 51. The other authors are shown in Fig. 5.

The entities that most finance research on the subject are the United States Department of Health Human Services, with 1203 studies (USA); the National Institutes of Health (NIH), with 1047 (USA); the European Commission, with 519 studies; National Institutes for Health Research (NIHR), with 420 (UK); and the Medical Research Council, with 314 (UK). These numbers reinforce the North American and English positions in the understanding and search for alternatives using cost and effectiveness within the area of health. In addition, Fig. 6 shows the twenty most relevant entities in financing research on the subject under analysis (Figs. 7 and 8).

As regards the citation of studies on cost and effectiveness, the number of citations has grown substantially each year since 1994, with the sum of the number of citations being 209,699 (191,319 


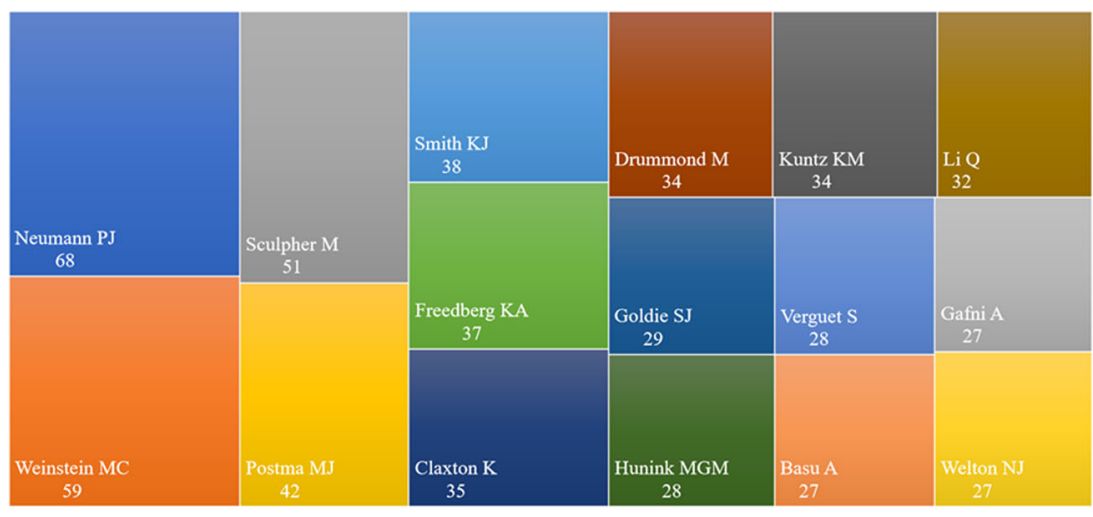

Fig. 5 Publications by author. Source: Web of Science, 2021.

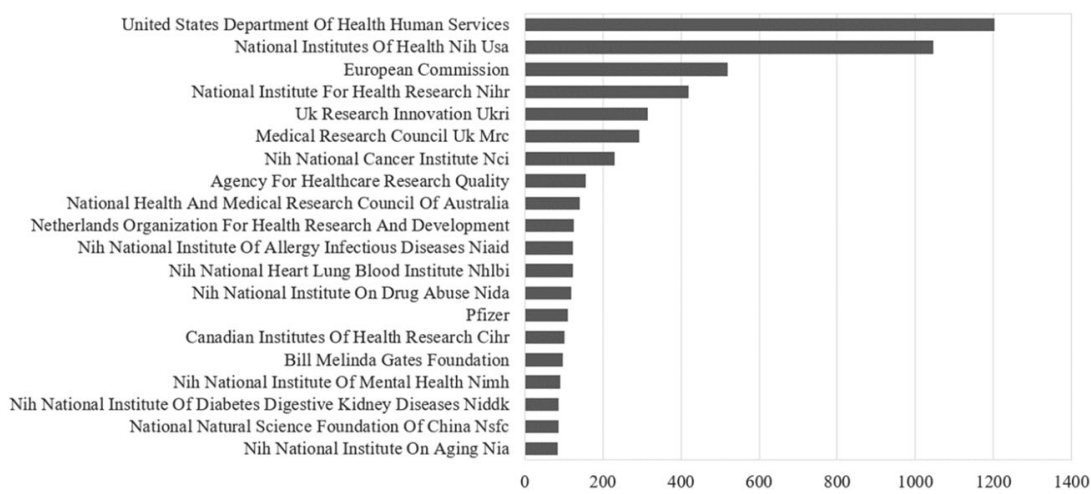

Fig. 6 Publications by funding entity. Source: Web of Science, 2021.

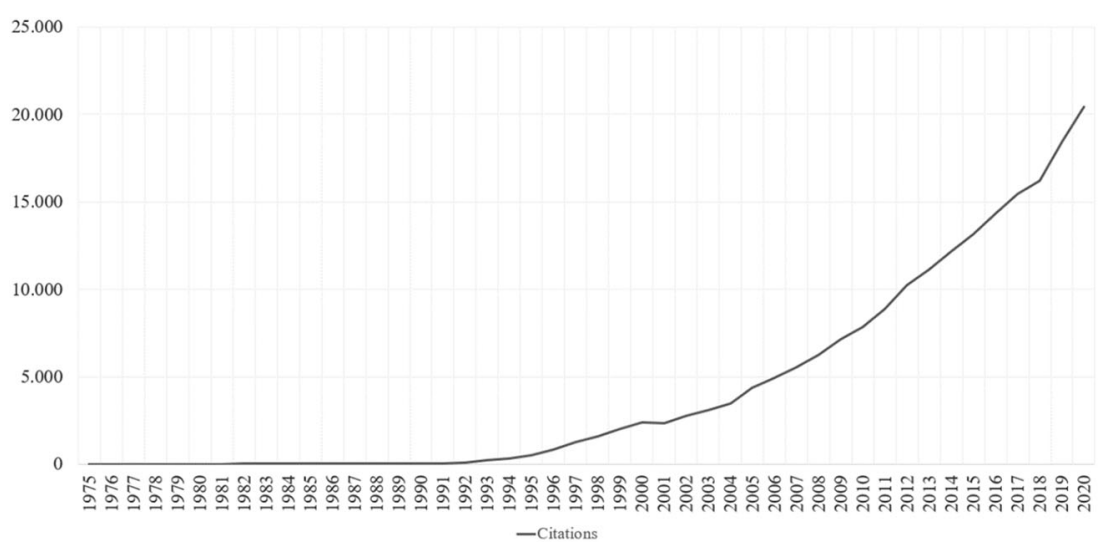

Fig. 7 Number of citations per year. Source: Web of Science, 2021.

excluding self-citations). The number of articles cited is 147,794 $(139,878$ excluding self-citations). In addition, we show a total of 7971 articles published by 2020 . These indicators demonstrate the growing relevance of CEA in health sector.

Table 3 shows the most cited articles, with emphasis on the articles Third Report of the National Cholesterol Education Program, with 11,035 citations as of 2020; Recommendations of the Panel on CostEffectiveness in Health and Medicine, with 1889 citations; Efficacy and Economic Assessment of Conventional Ventilatory Support Versus Extracorporeal Membrane, with 1651 citations; and Markov models in Medical Decision-Making, with 1596 citations. It is worth mentioning that the studies listed in this table are not only necessarily on technical basis for cost-effectiveness analyses, but also studies about specific health treatments and procedures to analyze costeffectiveness or its impact on this indicator.
Cost-effectiveness: network analysis. The VOSviewer tool was used, with 216.321 references found in this sample from 1994 to 2020. The criterion was at least 71 citations per study; thus. only links of significant relevance are shown on the map.

Figure 10 shows the network formed by 77 links divided into four clusters, divided by studies that are usually cited together and, eventually, by authors in the same line of research. In this case, the red cluster is formed by 22 links, and the most co-cited reference is the study Methods for the Economic Evaluation of Health Care. The second cluster is green, presenting 21 elements and notable links for the studies Cost-Effectiveness in Health and Medicine and Foundations of Cost-Effectiveness Analysis for Health and Medical Practices. The third cluster is blue and includes 17 components, with the most prominent study being Markov Models in Medical Decision-Making. The last cluster is yellow and has only four elements. 


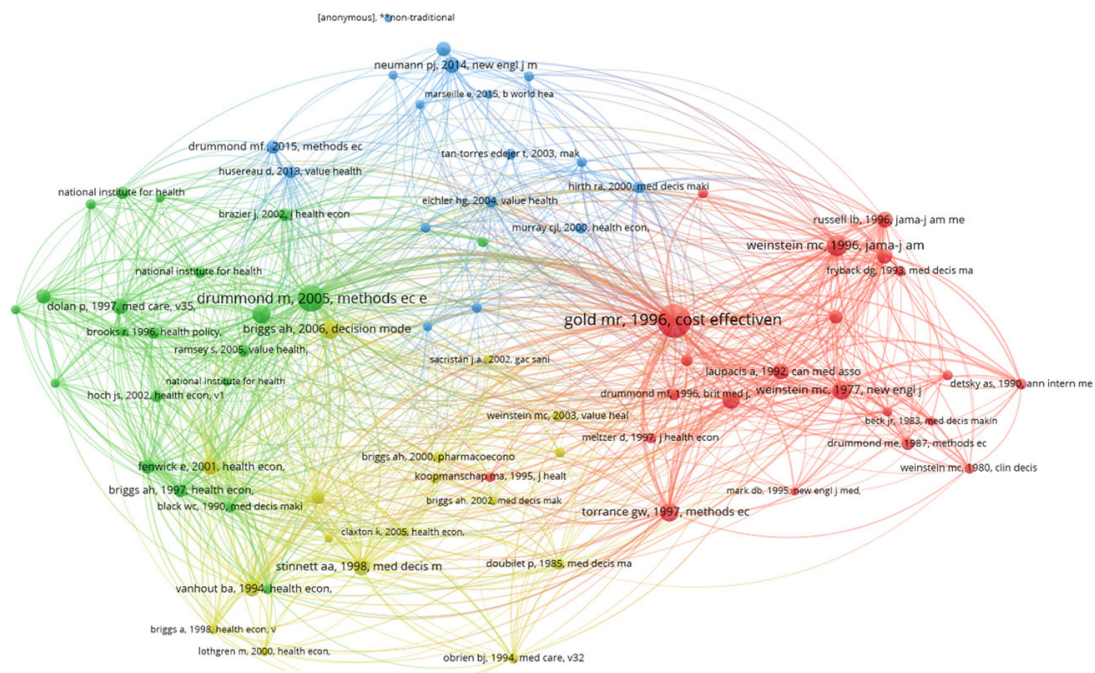

Fig. 8 Co-citation network. Source: Authors.

\section{Table 3 Citations by article.}

\section{Article title}

Third Report Of The National Cholesterol Education Program (Ncep) Expert Panel On

Detection, Evaluation, And Treatment Of High Blood Cholesterol In Adults (Adult

Treatment Panel III)

Recommendations Of The Panel On Cost-Effectiveness In Health And Medicine

Efficacy And Economic Assessment Of Conventional Ventilatory Support Versus

Extracorporeal Membrane Oxygenation For Severe Adult Respiratory Failure (Cesar): A

Multicentre Randomized Controlled Trial

Markov-Models In Medical Decision-Making

Foundations Of Cost-Effectiveness Analysis For Health And Medical Practices

Familial Hypercholesterolemia Is Underdiagnosed And Undertreated In The General

Population: Guidance For Clinicians To Prevent Coronary Heart Disease

How Attractive Does A New Technology Have To Be To Warrant Adoption And

Utilization - Tentative Guidelines For Using Clinical And Economic Evaluations

Hepatocellular Carcinoma

The Role Of Cost-Effectiveness Analysis In Health And Medicine

Venous Thromboembolism (Vte) In Europe - The Number Of Vte Events And

Associated Morbidity And Mortality

Source: adapted from Web of Science, 2021

Most studies in this network are focused on methods of economic evaluation in health or CEA procedures. As they are reference works of this sampling, it is possible to consider these studies as basic and fundamental to the development of the logic of this subject.

Table 4 shows the importance and impact of each network node in absolute numbers. In this case, only the top ten are demonstrated, but it is interesting to compare this with the graph with the highest number of citations per study (Fig. 9). Neither are the most cited studies mentioned as references in this sample and vice versa, nor are all co-citation references in the list of citations.

Figure 9 shows a co-citation network. The criterion was that each author would have a minimum number of 75 citations, and that parameter resulted in 220 links. This network has 6 clusters: the first contains 73 links highlighted in red, the second has 53 links in green, the third 37 links in blue, the fourth 28 links in yellow, the fifth 24 links in purple, and the sixth 5 links in light. As highlighted earlier, this group of authors is the most influential in this sample, as they were the most cited by the studies, possibly being considered basic or as having an essential logic for theoretical foundation and, consequently, being necessary for CEA development. In addition, it is reasonable to believe that the colors of each cluster indicate the specific domains of the theme.

Figure 10 shows the keyword density. In this analysis, the criterium was a minimum occurrence of 70 keyword mentions, with a total of 122 links. The relationship between CEA and other relevant terms is clear, indicating great affinity with health terms and an interaction regarding strategy, management, efficiency, results, and decision-making. This shows the importance of using CAE to improve competitive issues in institutions and create value within an institution or even within the health sector.

Figure 11 shows the same characteristics; however, the view mode is changed. In this network, in addition to clusters, connection strength between links is shown, as is impact, demonstrated by diameter. There is an overlap of colors that displays a color scale for the year; that is, it evaluates the year in which the keyword appeared. This analysis shows the progression of the theme: for example, the oldest topics are characterized by the cluster in purple, up to 2009, with keywords such as costeffectiveness analysis, healthcare, medicine being the first study subjects. Over time, terms such as quality of life, an effect 


\section{Table 4 Co-citation reference table.}

\section{Reference}

Foundations of Cost-Effectiveness Analysis for Health and Medical Practices 632

Markov Models in Medical Decision-Making: A Practical Guide 376

How attractive does a new technology have to be to warrant adoption and utilization? 518

Decision Modeling for Health Economic Evaluation 349

Net Health Benefits: A New Framework for the Analysis of Uncertainty in Cost-Effectiveness Analysis 516

The role of cost-effectiveness analysis in health and medicine 561

Modeling Valuations for EuroQol Health States 462

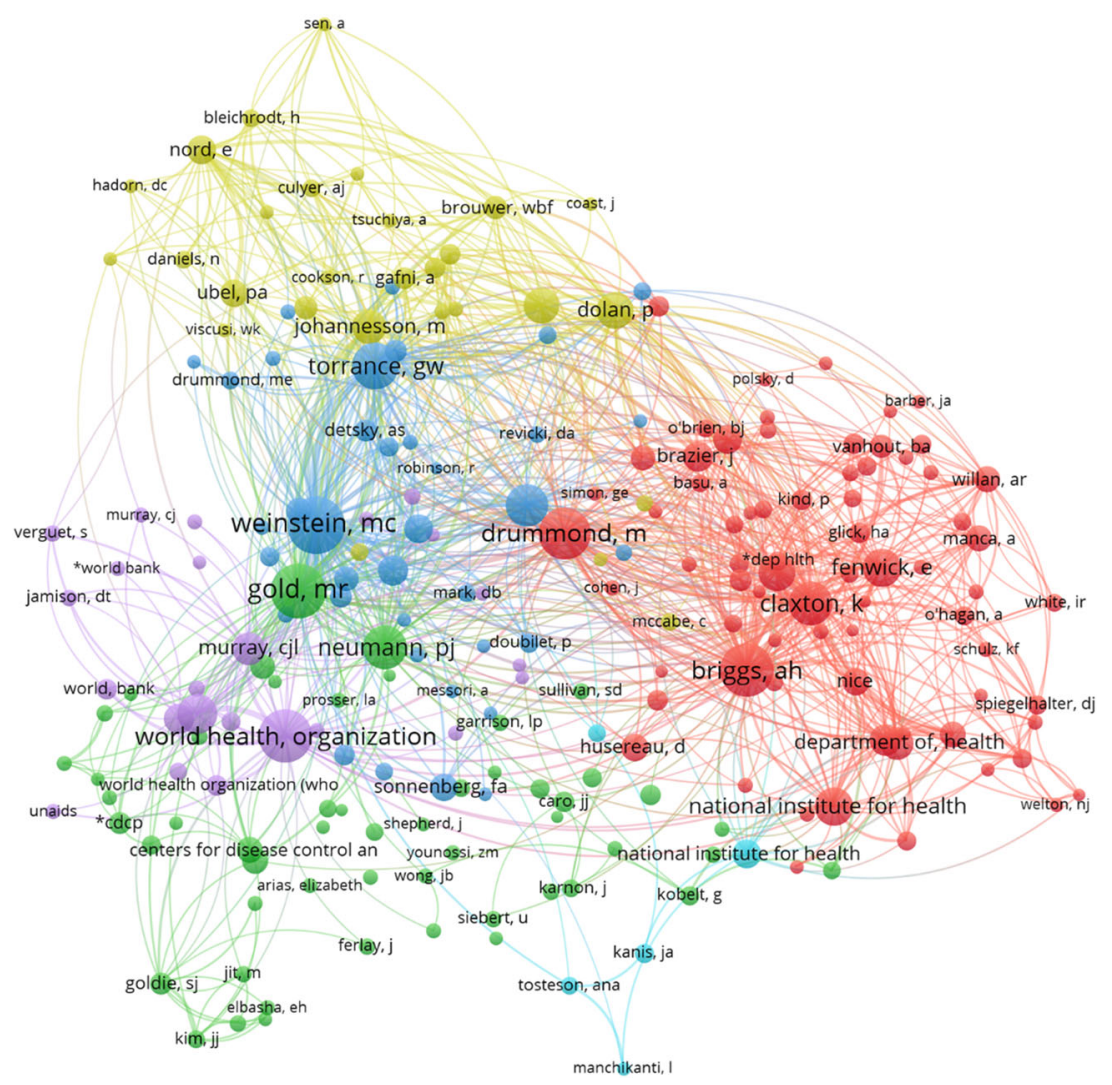

Fig. 9 Co-citation network by authors. Source: Authors.

indicator to compare therapies from different classes, have been included in addition to newer terms such as management, impact, and people, shown in yellow, which indicates the progress of the theme. It is undoubtedly an analysis that contributes to enriching future research and encourages more studies on this subject, inevitably inferring the absence of a relationship between costeffectiveness and themes of high contemporary relevance to the area of health sector, such as telemedicine, telehealth, cost on the part of the patient, artificial intelligence, robotics, clinical simulation, augmented reality, among others (Cruz et al., 2021).

\section{Discussion}

Currently, CEA is an indispensable theme due to the social reality of the world, more specifically in the case of health sector. Technologies are advancing rapidly, new healthcare alternatives are discovered every day, and the population is increasingly demanding assistance that prolongs life expectancy and, at the same time, provides well-being.
Despite the need for accessible and quality assistance in health sector, its demands incur the use of resources that are almost always scarce that is, both private and public institutions have limited resources (Pit et al., 2016). For this reason, economic evaluation was adapted to the health sector as a means of supplying managers with reliable decision-making indicators, resulting in a more efficient distribution of the available resources in treatments and structure with better costeffectiveness. Despite the high prominence of this subject in the academic world, the theme still lacks effective health sector applications worldwide. In this sense, with the initial purpose of contributing to the understanding of the theoretical status for further applied progression of the theme, this research aimed to increase the transfer of relevant information about CEA and to encourage professionals and students to understand in detail the characteristics of this field.

Therefore, this modest bibliometric analysis showed that the number of publications more than doubled from 2009 to 2020, growing from 294 to 717 . This suggests concerns about the 


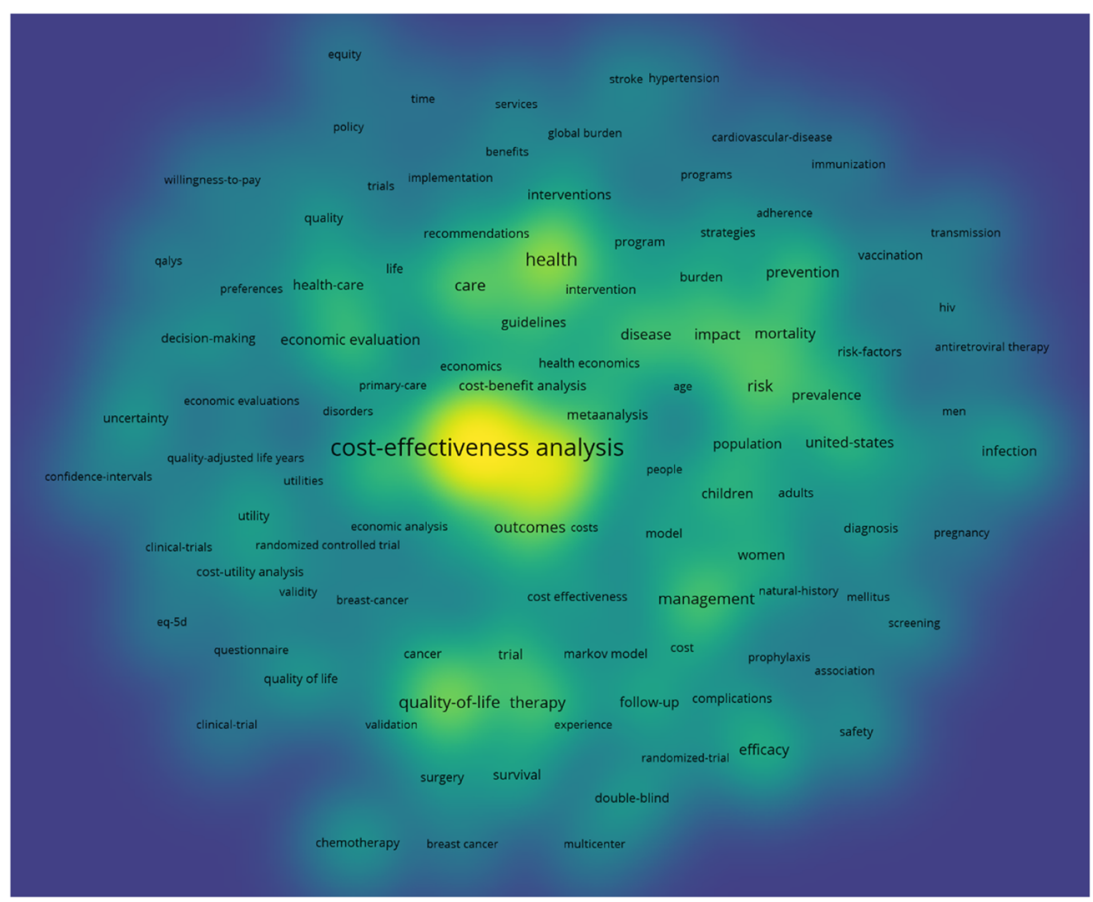

Fig. 10 Keyword density. Source: Authors.

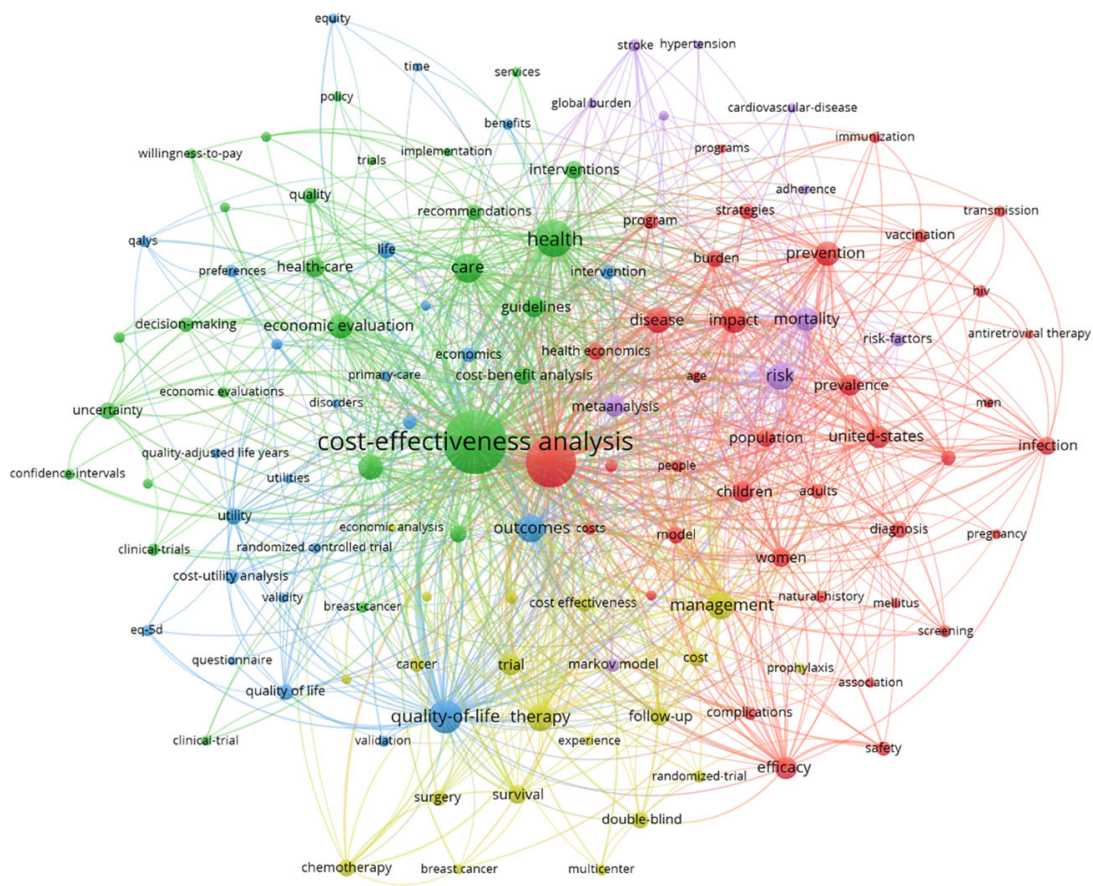

Fig. 11 Keyword network. Source: Authors.

progression of knowledge of CEA use, mainly regarding treatment applicability and analysis. The theme, although contemporary, can be considered mature, with the first publication in 1977. Despite this, it is still a branch that is growing rapidly: the United States, England, and Canada figure as the most relevant countries in the theme, both in the number of publications and in the origin of resources to finance research in the area. The University of London and Harvard University are the main research institutions in the field, and P. J. Neumann, M. C. Weinstein, and M. Schulpher are the researchers with the largest number of publications on the topic. The articles Performance Third Report of National Cholesterol Education Program, Recommendations of the Panel on Cost-Effectiveness in Health Medicine, and Markov Models in Medical Decision-Making-A Practical Guide are the studies with the highest number of citations in the domain of CEA.

Network mapping highlighted relevant characteristics to understand academic studies on CEA. In this sense, the analysis of citations by reference in this sample showed that the authors and studies in the list do not necessarily reflect the articles with the most citations. However, they are the most influential studies and authors, consequently supporting these articles with crucial 
logic and concepts. Furthermore, the constitution of these clusters, whether by authors or references, possibly indicates a particular line of research or research area since these authors are usually mentioned together.

Three hypotheses can be verified regarding keywords. The first shows the keywords most used in these studies, cost-effectiveness analysis, economic evaluation, and quality of life, through visualization by density of words; the second shows that older research relates the theme to the keywords cost-effectiveness analysis, healthcare, and medicine through the network of keywords with overlapping colors over time, with more recent studies presenting words such as quality of life, management, impact, and people. Finally, the third hypothesis is evidenced by the absence of a relationship between cost and effectiveness with emerging themes in the health field, such as telemedicine, telehealth, artificial intelligence, cost on the part of the patient, robotics, clinical simulation, and augmented reality. This absence denotes a great challenge and opportunity for studies linking the analysis of cost and effectiveness in health sector with the latest health alternatives to clarify their effective contributions to improve access to and the quality of assistance in public and private health sector.

Finally, this article highlights useful information as well as relevant CEA aspects, guiding researchers through the main scenarios and theoretical trends of the theme in search of the technical clarification of conceptual approaches and research already applied and seeking new challenges for the development of studies that can promote greater health service access and quality in the world.

\section{Data availability}

All data generated or analyzed during this study are included in this published article and its supplementary information files.

Received: 29 April 2021; Accepted: 14 October 2021;

Published online: 29 October 2021

\section{References}

Briggs A, Claxton K, Sculpher M (2006) Decision modelling for health economic evaluation. Oxford University Press

Cruz JAW, Cunha MAVC, Moraes TP, Tuon FF, Linhares GP, Gomide AL, Marques S (2021) Brazilian private health system: history, scenarios, and trends, PREPRINT BMC Health Services Research. https://doi.org/10.21203/rs.3.rs-726814/v1

Devers KJ, Brewster LR, Casalino LP (2003) Changes in hospital competitive strategy: a new medical arms race? Health Serv Res 38:447-469. https:// doi.org/10.1111/1475-6773.00124

Drummond M, Sculpher M, Claxton K, Stoddart G, Torrance G (2015) Methods for economic evaluation of health care programmes. Oxford University Press, Oxford

Gasparetto J, Tuon FF, Oliveira DS, Zequinão T, Pipolo GR, Ribeiro GV, Benincá PD, Cruz JAW, Moraes TP (2019) Intravenous-to-oral antibiotic switch therapy: a cross-sectional study in critical care units. BMC Infect Dis, 19 (1). https://doi.org/10.1186/s12879-019-4280-0

Gray AM, Clarke PM, Wolstenholme JL, Wordsworth S (2010) Applied methods of cost-effectiveness analysis in healthcare. OUP Catalogue, Oxford University Press

IBGE (2021). https://www.ibge.gov.br. Accessed 21 Feb 2021

Jacobs R, Smith P, Street A (2006) Measuring efficiency in health care. Cambridge University Press, Cambridge, https://doi.org/10.1017/CBO9780511617492

Loesch G, Moraes TP, Cruz JAW, Pecoits Filho RFS, Barretti P, Figueiredo AEPL (2020) Public health investments and mortality risk in Brazilian peritoneal dialysis patients. Clin Kidney J 13(6). https://doi.org/10.1093/ckj/sfaa118
Loesch G, Cruz JAW, Gasparetto J, Oliveira DS, Telles JP, Tuon FF (2021) Cost minimization analysis of outpatient parenteral/oral antibiotic therapy at a trauma hospital: public health system. Infect Cont Hosp epidemiol 23(1). https://doi.org/10.1017/ice.2021.22

Meunning P (2008) Cost-effectiveness analyses in health: a practical approach. Jossey-Bass, San Francisco

Moreno E, Vázquez-Polo FJ, Negrín-Henández MA (2019) Cost-effectiveness analysis of medical treatments. CRC Press, Boca Raton

National Health Agency (2021). https://www.gov.br/ans/pt-br. Accessed 11 Feb 2021

Pit C, Goodman C, Hanson K (2016) Economic Evaluation in Global Perspective: A Bibliometric analysis of the recente literature. Health Econ. https://doi.org/ 10.1002/hec.3305

Sandri EC, Kumasaka JMVC, Cruz JAW, Cruzara G (2020) Avaliação do impacto social: um levantamento bibliométrico. Revista Teoria e Prática em Administração 11(1):106. https://doi.org/10.22478/ufpb.2238-104X.2021v11n1.52611

Secoli SR, Nita ME, Ono-Nita SK, Nobre M (2010) Avaliação de tecnologia em saúde II. A análise de custo-efetividade. Arquivos de Gastroenterologia 47(4):329. https://doi.org/10.1590/S0004-28032010000400002

Tuon FF, Telles JP, Gasparetto J, Zequinão T (2020) Antibiotic price rise and antibiotic stewardship programs-Stimulus or discouragement? Infect Cont Hosp Epidemiol 41(8):994. https://doi.org/10.1017/ice.2020.125

Tuon FF, Rocha JL, Gasparetto J (2019) Polymyxin B and colistin-the economic burden of nephrotoxicity against multidrug resistant bactéria 22(2): 158 . https://doi.org/10.1080/13696998.2018.1552431

Zequinão T, Gasparetto J, Oliveira DS, Silva GT, Telles JP, Tuon FF (2020) A broad-spectrum beta-lactam-sparing stewardship program in a middleincome country public hospital: antibiotic use and expenditure outcomes and antimicrobial susceptibility profiles. Braz J Infect Dis 24(3):221. https:// doi.org/10.1016/j.bjid.2020.05.005

Vuong QH, Ho TM, Nguyen HK et al. (2018) Healthcare consumers' sensitivity to costs: a reflection on behavioural economics from an emerging market. Palgrave Commun 4:70. https://doi.org/10.1057/s41599-018-0127-3

Vuong QH (2015) Be rich or don't be sick: estimating Vietnamese patients' risk of falling into destitution. SpringerPlus 4:529. https://doi.org/10.1186/s40064015-1279-x

\section{Acknowledgements}

None.

\section{Competing interests}

The authors declare no competing interests.

\section{Additional information}

Supplementary information The online version contains supplementary material available at https://doi.org/10.1057/s41599-021-00940-5.

Correspondence and requests for materials should be addressed to June Alisson Westarb Cruz.

Reprints and permission information is available at http://www.nature.com/reprints

Publisher's note Springer Nature remains neutral with regard to jurisdictional claims in published maps and institutional affiliations.

Open Access This article is licensed under a Creative Commons Attribution 4.0 International License, which permits use, sharing, adaptation, distribution and reproduction in any medium or format, as long as you give appropriate credit to the original author(s) and the source, provide a link to the Creative Commons license, and indicate if changes were made. The images or other third party material in this article are included in the article's Creative Commons license, unless indicated otherwise in a credit line to the material. If material is not included in the article's Creative Commons license and your intended use is not permitted by statutory regulation or exceeds the permitted use, you will need to obtain permission directly from the copyright holder. To view a copy of this license, visit http://creativecommons.org/ licenses/by/4.0/.

(C) The Author(s) 2021 